\title{
EXTRACTING BUILT-UP FEATURES IN COMPLEX BIOPHYSICAL ENVIRONMENTS BY USING A LANDSAT BANDS RATIO
}

\author{
Alfred Homère Ngandam Mfondoum*1, ${ }^{*}$, Paul Gérard Gbetkom ${ }^{3}$ Ryan Cooper ${ }^{4}$, Sofia Hakdaoui ${ }^{5}$, \\ Mamane Barkawi Mansour Badamassi ${ }^{6}$ \\ 1 StatsN'Maps, Private Consulting Firm, Dallas, Texas, USA. stats.n.maps.expertise@gmail.com \\ 2 Department of Geography, University of Yaoundé I, Yaoundé, Cameroon. Alfred.homere@ gmail.com \\ ${ }^{3}$ Department of Geography, University of Aix-Marseille, Marseille, France. Paul-gerard.gbetkom@etu.univ-amu.fr \\ ${ }^{4}$ Erik Jonsson School of Engineering and Computer Science, University of Texas in Dallas, Dallas, Texas 75080, USA. \\ Rdc190001@utdallas.edu \\ ${ }^{5}$ Earth Observation Department, Geo-Biodiversity and Natural Patrimony Laboratory, \\ Geophysics, Natural Patrimony and Green Chemistry Research Center, Scientific Institute, Mohamed V University, Rabat, \\ Morocco.s.hakdaoui@gmail.com \\ ${ }^{6}$ Laboratory of Botanic, Mycology and Environment, Mohammed V University, Rabat, Morocco. \\ barkawimansour@yahoo.fr
}

Keywords: Built-up, urban mixed pixels, Normalized Difference Built-up and Surroundings Unmixing Index, Landsat-8, Yaoundé, Cameroon,

\begin{abstract}
:
This paper addresses the remote sensing challenging field of urban mixed pixels on a medium spatial resolution satellite data. The tentatively named Normalized Difference Built-up and Surroundings Unmixing Index (NDBSUI) is proposed by using Landsat-8 Operational Land Imager (OLI) bands. It uses the Shortwave Infrared 2 (SWIR2) as the main wavelength, the SWIR1 with the red wavelengths, for the built-up extraction. A ratio is computed based on the normalization process and the application is made on six cities with different urban and environmental characteristics. The built-up of the experimental site of Yaoundé is extracted with an overall accuracy of $95.51 \%$ and a kappa coefficient of 0.90 . The NDBSUI is validated over five other sites, chosen according to Cameroon's bioclimatic zoning. The results are satisfactory for the cities of Yokadouma and Kumba in the bimodal and monomodal rainfall zones, where overall accuracies are up to $98.9 \%$ and $97.5 \%$, with kappa coefficients of 0.88 and 0.94 respectively, although these values are close to those of three other indices. However, in the cities of Foumban, Ngaoundéré and Garoua, representing the western highlands, the high Guinea savannah and the Sudano-sahelian zones where built-up is more confused with soil features, overall accuracies of $97.06 \%, 95.29 \%$ and $74.86 \%$, corresponding to $0.918,0.89$ and 0.42 kappa coefficients were recorded. Difference of accuracy with EBBI, NDBI and UI are up to $31.66 \%$, confirming the NDBSUI efficiency to automate built-up extraction and unmixing from surrounding noises with less biases.
\end{abstract}

\section{INTRODUCTION}

Every urban area is heterogeneous, mixing diverse land cover types and materials, such as road, rooftop, vegetated area, bare soil, water, which are quite different from rural and natural environment (Schueler, 1994). This usually leads to mixed pixels, known as a picture element that has a digital number representing the average energy emitted or reflected from several different surfaces occurring within the area represented, by the pixel (Bangira et al., 2017). Urban remote sensing offers several solutions to address these issues, mainly using spectral indices-based algorithms and decomposition methods.

Some simple indices based on ratio or algebraic crossings of basic spectral bands enable to automate the mapping of human settlements. It is the case of the urban index, UI (Kawamura et al., 1996), the normalized difference builtup index, NDBI (Zha et al., 2003) and the new built-up index, NBI (Chen et al., 2010). Some other focus on builtup and bare soil differentiation, as the Enhanced Built-Up and Bareness Index, EBBI (As-syakur, 2012), and the normalized difference tillage index, NDTI (Ettehadi et al., 2019).

\footnotetext{
* Corresponding author (stats.n.maps.expertise@ gmail.com)
}

Further, the composed indices based on thematic indexderived bands and existing algorithms modifications are interested in noise reduction. Amongst them are the indexbased built-up index, IBI $(\mathrm{Xu}, 2008)$ and the dry built-up index, DBI (Rasul et al., 2018). To address this issue in terms of imperviousness, the normalized difference impervious surface index, NDISI (Hanqiu, 2010) and its derivatives were proposed.

All the above indices are helpful to highlight built-up areas. However, uncertainties and biases remain in separating bare land from built-up. The main reason is that spectral signatures of ISAs are like those of soils, sands and rocks. In developing countries, the extent of built-up in makeshifts and raw material, as well as unpaved (dusty/muddy) roads (Fig.1) inside and near cities, added to the use of freely available satellite images of coarse or moderate spatial resolution (MODIS, Landsat) in unfunded researches emphasize these issues. Consequently, there is a high spatial and spectral diversity of surface materials that are more challenging for remote sensing analysis (Herold et al., 2003). 


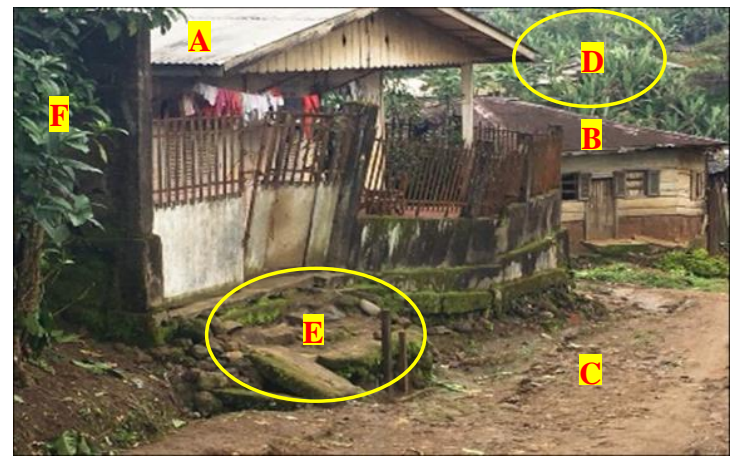

Figure 1. A mixed built-up environment. $A=B r i g h t$ aluminum roof; $B=$ Rusted aluminum roof; $C=$ Unpaved (Dusty/Muddy) road/Soils/Stones; D=Bright and rusted aluminum roofs mixed with bananas plants;

E=Pavements mixed with stones and bare soils; $F=$ Natural vegetation.

From the above, the main goal of this research is to unmix built-up and surrounding land cover features, i.e. bare soils, vegetation and water. The two specific goals are the following: i) extract the built-up features from a spectral bands ratio in mixed-housing and built-up material context; ii) dissociate interweaved spectral signals of built-up and natural surrounding features to map the urban area with the highest accuracy.

\section{METHODOLOGY}

\subsection{Research location}

The experiments were conducted in Cameroon (Central Africa), located between latitude $2^{\circ} 00^{\prime} 0 "{ }^{\prime \prime}-13^{\circ} 00^{\prime} 0 " \mathrm{~N}$ and longitude $8^{\circ} 00^{\prime} 0 " 0^{\prime \prime}-16^{\circ} 00^{\prime} 0 " \mathrm{E}$ (Fig. $2 a$.). The experimental site is Yaoundé, the political capital. This city belongs to the humid forest zone with bimodal rainfall, it is located between latitude $3^{\circ} 52^{\prime} 00.0^{\prime \prime} \mathrm{N}$ and longitude $11^{\circ} 31^{\prime} 00.0^{\prime \prime} \mathrm{E}$ (Fig. 2b.), its population is 2.5 million inhabitants and its area covers approximately 31750 hectares. Yaoundé is subject to urban sprawl due to an outdated master plan and a lack of further planning as other cities in Cameroon. Three areas of interest (AOIs) extracted in Yaoundé enable a good view of the sprawl as well as mixture. (Fig.2b)

For the purpose of cross validation, five other cities are inserted in the study. The cities of Yokadouma, Kumba, Foumban, Ngaoundéré and Garoua are selected according to Cameroon's bioclimatic zoning (Fig. 2.c to 2.g). Indeed, the specific conditions of high or low forest cover and consequently the related soil exposure, as well as altitude, should help to validate the suitability of the proposed index application.

\subsection{Datasets acquisition and pre-processing}

The data used are satellite images from Landsat 8 Operational Land Imager-Thermal infrared sensors (Tab.1). The scenes used were downloaded for the dry season from the United States Geological Survey website and displayed under false colour composite NIR-RedGreen (see fig. $2 b-g$ ) (Tabl.1). For the purpose of preprocessing, bands blue, green, red, near infrared, and both shortwave infrareds were stacked. Applying the Cosine Solar TAUZ (COST) radiometric calibration model of Chavez (1996), the DNs were converted from at-sensor radiance to top-of-atmosphere (TOA) reflectance. Atmospheric corrections and haze reduction have helped to remove other noises and then approximate values of land surface reflectance. The last step concerned the topographic correction to lower altitude artifacts.

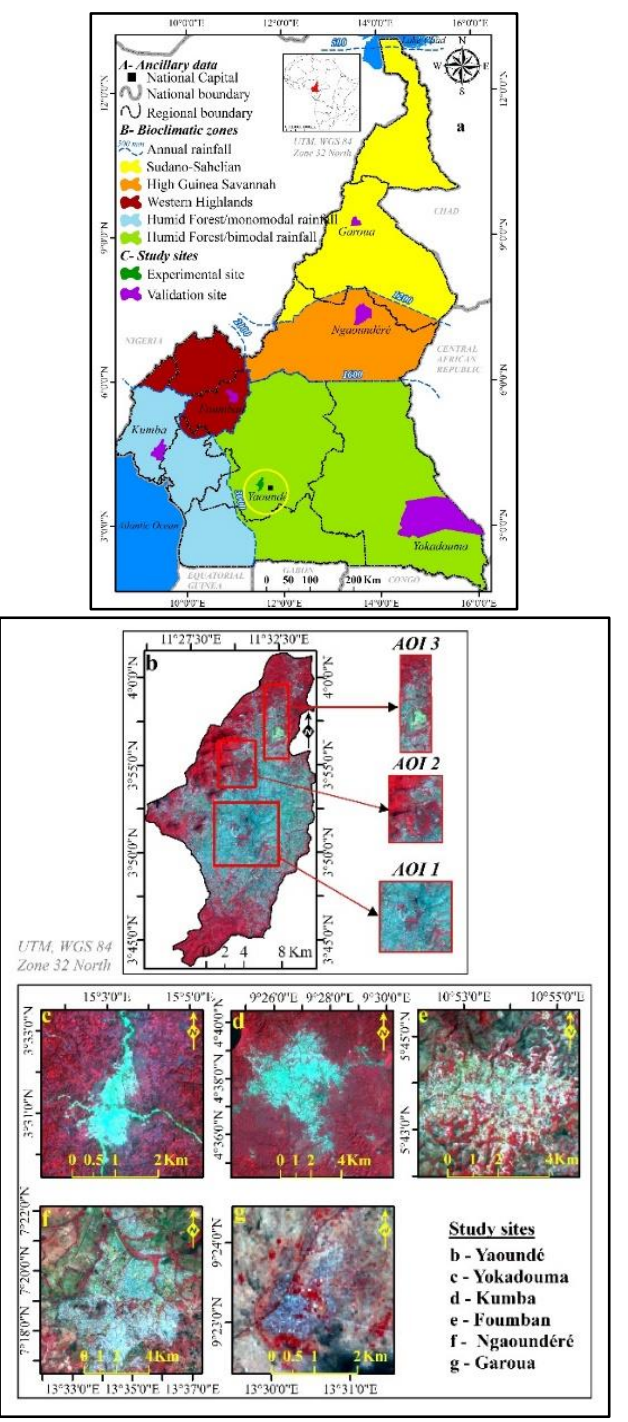

Figure 2. The study area

\begin{tabular}{|l|l|l|}
\hline Site & Scene ID & $\begin{array}{l}\text { Center } \\
\text { Time }\end{array}$ \\
\hline Yaoundé & LC81850572018004LGN00 & $09: 26$ \\
\hline Yokadouma & LC81820582019002LGN00 & $09: 14$ \\
\hline Kumba & LC81870572019005LGN00 & $09: 38$ \\
\hline Foumban & LC81860562019030LGN00 & $09: 32$ \\
\hline Ngaoundéré & LC81840552019064LGN00 & $09: 19$ \\
\hline Garoua & LC81850542019087LGN00 & $09: 25$ \\
\hline
\end{tabular}

Table 1. Scenes information

\subsection{Processing}

\subsubsection{The spectral separability efficiency of SWIR2}

According to the experiences of Herold et al. (2003) and the USGS spectral library (Kokaly et al., 2017), there are several visible and infrared windows of the electromagnetic spectrum where manmade settlements and artificial surfaces reflect the best. The most suitable for the built-up separability from surroundings are in the 
SWIR region located at $1710,1740,1960,2000,2040$, 2200,2340 and 2460 nanometers. To assess this statement on the study sites, spectral curves of main land cover objects were extracted, i.e. built-up, vegetation, wet soils/Swamps, dry soils/rocks and water bodies. (Fig.3)

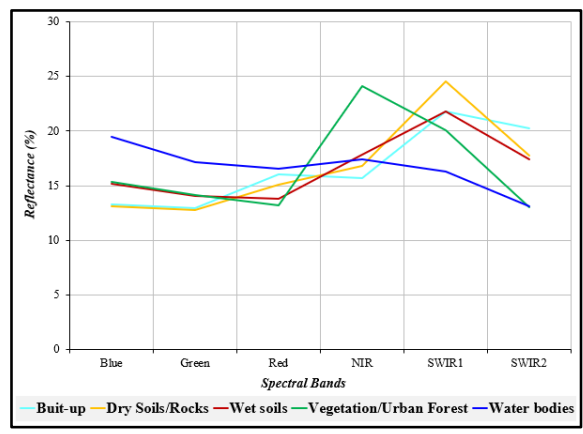

Figure 3. Spectral curves in Yaoundé

It can be noticed that the high unmixed reflectance of built-up takes place in the SWIR2 band (2107-2294 nm), its highest reflectance is in the SWIR1 band (1566- 1651 $\mathrm{nm}$ ), but covered by the soil features ; while the red band (636-673 nm) shows the best built-up reflectance in the visible wavelengths despite the water bodies noise. A thorough assessment was performed through pixels sampling on the three areas of interest. Regardless of the dominating land cover class, on 10,000 pixels and from the stretching approach, the lower frequencies (counts) of the red band and the medium for the SWIR1 correspond to higher for SWIR2. (Fig.4 left column). While on 2,500 pixels, the values of SWIR2 digital numbers, DNs, are discriminated from the two other bands that are higher or lower (Fig.4; right column)

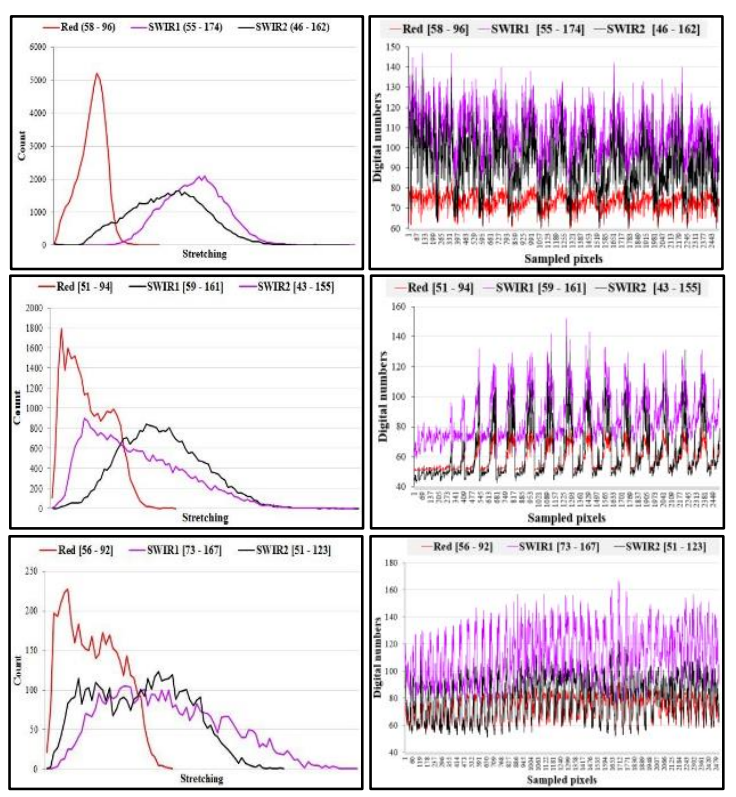

Figure 4. Status of red, SWIR1 and SWIR2 discrimination.

\subsubsection{Built-up features extraction from the red and SWIR1 bands}

The built-up information in the red and SWIR1 is important, but highly mixed with other features. The intent is to create a new pixel representing the built-up in these two bands and add it to the SWIR2 built-up information.
The approach through the geometric mean was chosen, because in image processing, the geometric mean filter is meant to smooth and reduce noise (Gonzalez, 2002). The output image $\mathrm{G}(x, y)$ is given by:

$$
G(x, y)=\left[\prod_{i, j \in S} S(i, j)\right]^{\frac{1}{m n}}
$$

Where $\mathrm{S}(x, y)$ is the original image, and the filter mask is $m$ by $n$ pixels. Each pixel of the output image at point $(x, y)$ is given by the product of the pixels within the geometric mean mask raised to the power of $\frac{\mathbf{1}}{\mathbf{m n}}$ (Gonzalez, 2002).

The graphical representation and mathematical expression of the geometrical mean that eases the red and SWIR1 implementation is the following: (Fig.5)

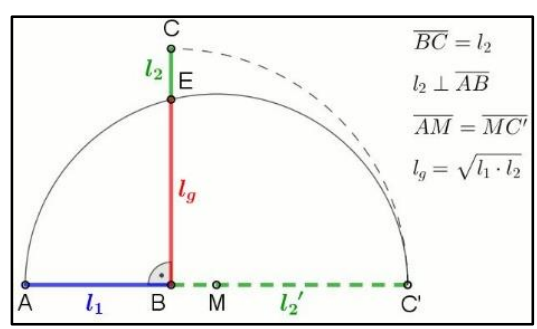

Figure 5. The geometric mean illustration

In addition, while proposing the EBBI algorithm, Assyakur (2012) recognized that a root function enables to cluster the numbers that contrast identical objects based on the different levels of reflectance values. Therefore, the equation for the new pixel was posed as follows:

$$
\operatorname{G(Red,SWIR1)}=\sqrt{\operatorname{Red} * S W I R 1}
$$

Where Red is $\boldsymbol{l}_{\mathbf{1}}$, according to its lower built-up information than SWIR1 which considered $\boldsymbol{l}_{\mathbf{2}}$.

The sampling of built-up pixels on the stacked images confirms the value of the pixel created to be newly informative. (Fig.6)

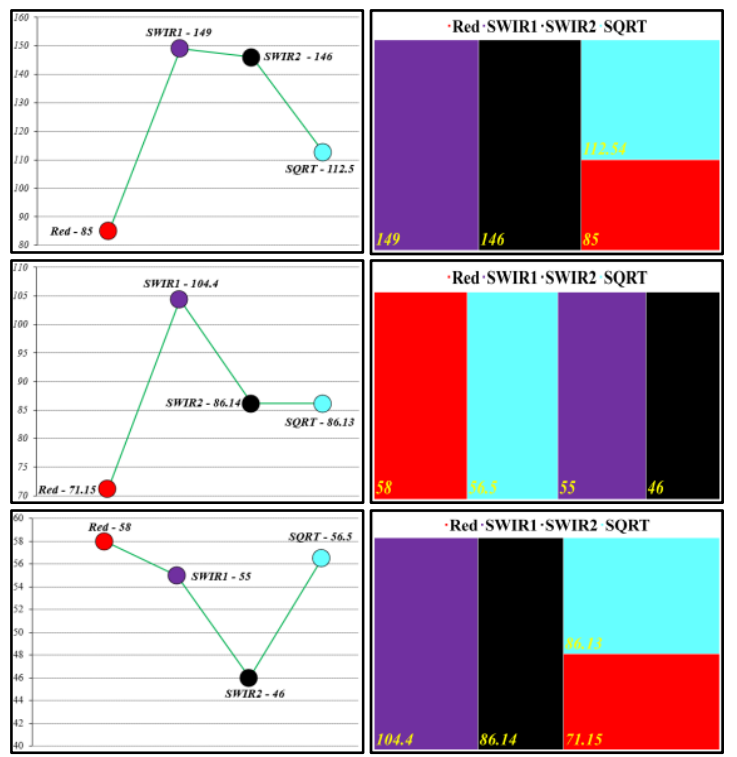

Figure 6. Three built-up pixels (left) and their informative values (right). 
When the SWIR2 is regressed by the red, SWIR1 and the new band, the determination coefficients, $\boldsymbol{r}^{2}$ are respectively $0.83,0.88$ and 0.93 . (Fig.7)
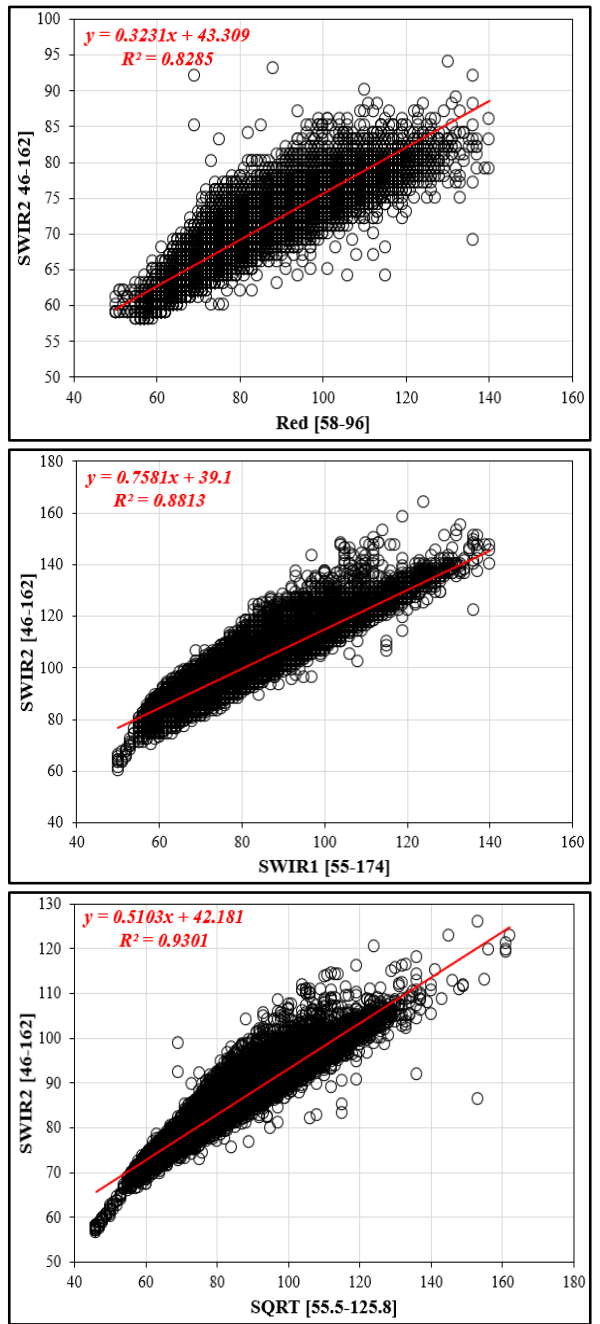

Figure 7. Linear regressions assessment

\subsubsection{Technical assumptions and proposed method}

The tests and approaches above have helped to formulate three technical assumptions justifying the proposed process:

i) the SWIR2 is the main spectral band for built-up extraction with less noises;

ii) the square root band is the best value to extract the built-up from red and SWIRI bands with less noise;

iii) the addition of the two previous, and the subtraction of the whole red and SWIRI bands will minimize the mixed-pixel noise.

The statements on the built-up extraction and noise reduction led to the formulation of the Normalized Difference Built-up and Surroundings Unmixing Index, $N D B S U I$ as the following ratio:

$N D B S U I=\frac{(S W I R 2+\sqrt{\operatorname{Red} * S W I R 1})-(\operatorname{Red}+S W I R 1)}{(S W I R 2+\sqrt{\operatorname{Red} * S W I R 1})+(\operatorname{Red}+S W I R 1)}$
Its efficiency in mapping the built-up was assessed using the overall accuracy and the kappa coefficient (USGS, 1990).

\section{RESULTS AND DISCUSSIONS}

\subsection{Visual patterns and accuracy assessment}

The NDBSUI map is positively stretched [0.08-0.245] and its visual trends match the built-up on the stacked image. Using the Support Vector Machine algorithm, the stacked image as well as the NDBSUI were classified. Then after, the stratified random sampling technique experimented by Congalton (2009) was used to assess the index accuracy displaying 300 locations. From that, the NDBSUI was proven efficient in matching the built-up area with an overall accuracy of $95.5 \%$ and a kappa coefficient of 0.908. (Fig.8)

When zooming into the AOIs, the index image has shown ability to clearly discriminate the others land cover categories from the built-up (Fig.9). The accuracy assessment was performed on 100 locations (pixels) for each AOI. The OA are $100 \%, 96.59 \%$ and $96.58 \%$, with $\mathrm{KC}$ of $1,0.92$ and 0.93 , respectively, in the built-up, wet soil and dry soil/rocky dominating AOIs. It gives an average $\mathrm{OA}$ of $97.8 \%$, for a $\mathrm{KC}$ of 0.95 .

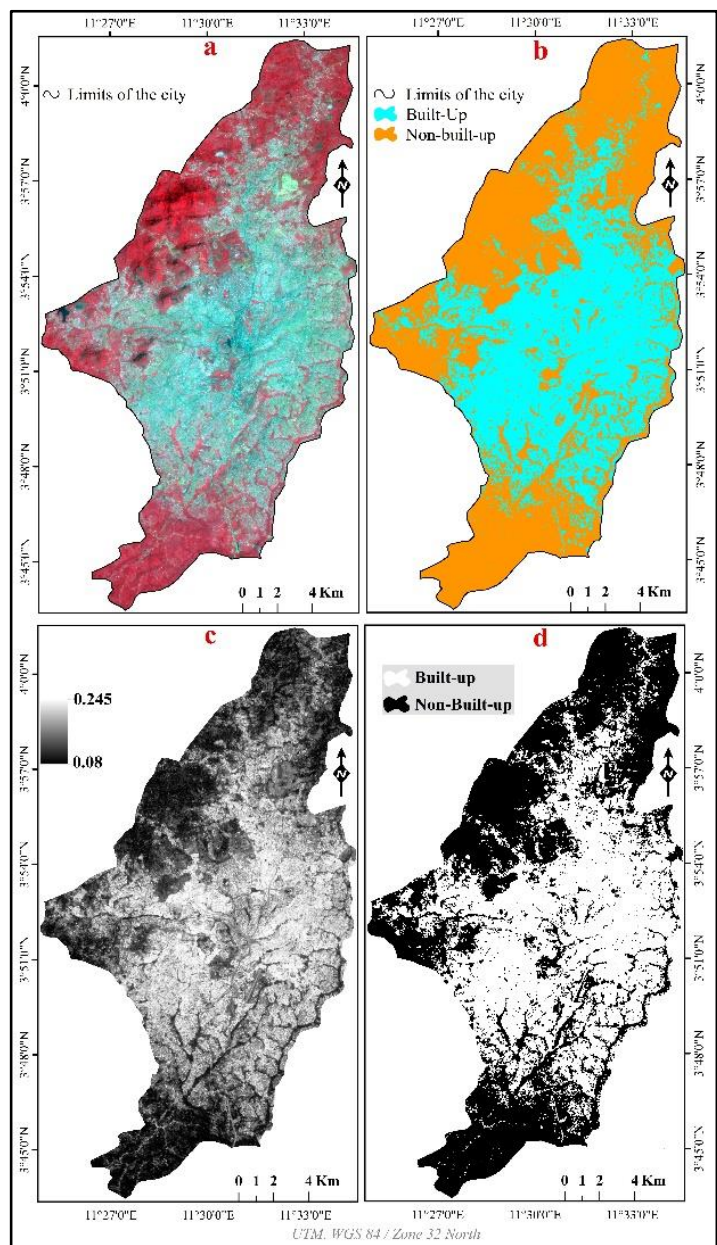

Figure 8. Visual results of the built-up extraction. From left to right and top to down, the stacked image $(a)$, the binary classification image highlighting built-up $(b)$, the NDBSUI stretched $(\boldsymbol{c})$ and binary views $(d)$. 


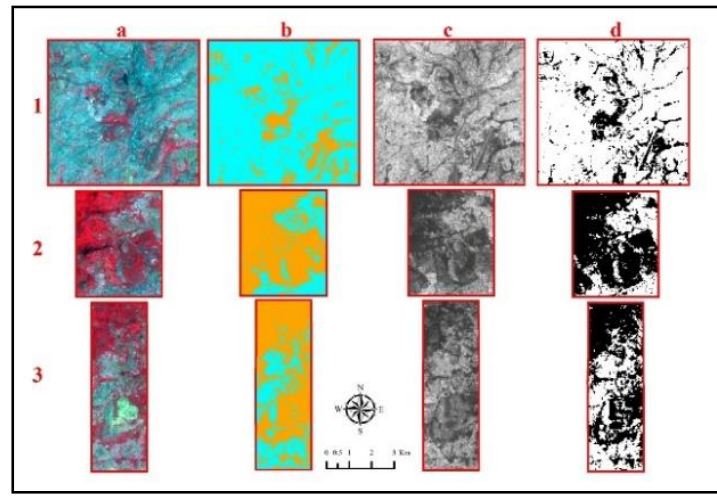

Figure 9. The NDBSUI unmixing suitability. 1,2 and 3 represent the three AOIs while $\boldsymbol{a}, \boldsymbol{b}, \boldsymbol{c}$ and $\boldsymbol{d}$ are the stacked, binary classification, NDBSUI stretched and binary views.

\subsection{Comparative efficiency with existing methods}

Further, the suitability of the NDBSUI in highlighting built-up features was assessed in comparison to the EBBI, NDBI and UI (Fig.10). The choice of these three indices is justified by their utilization of SWIR1 or SWIR2 as main wavelengths for built-up extraction. The built-up extraction trends are generally the same. However, from its stretching [0.08-0.245], the NDBSUI extract the builtup only in positive ranges, conversely to the EBBI [0.41817-0.659394], NDBI [-0.204301-0.340909] and UI [0.4-0.491228] (Fig.10, Top line). To compare their accuracies, 300 locations were also displayed using the binary images. They gave OA of $93.5 \%, 92.86 \%$ and $92.81 \%$, with $\mathrm{KC}$ of $0.87,0.8564$ and 0.8561 respectively for EBBI, NDBI and UI (Tabl.2).

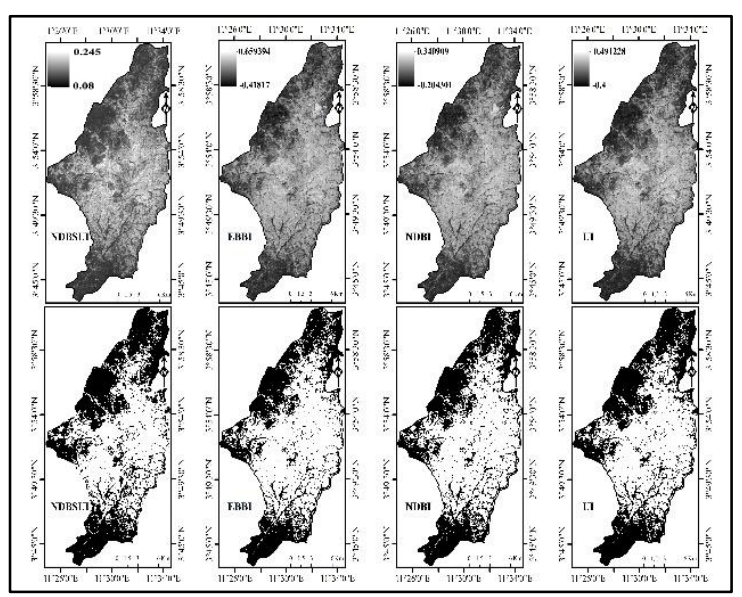

Figure 10. Indices maps. The top line shows stretched maps and bottom binary ones.

\begin{tabular}{|c|c|c|c|c|c|c|}
\hline \multirow{2}{*}{ Index } & \multicolumn{2}{|c|}{ Built-up } & \multicolumn{2}{|c|}{ Non-built-up } & \multirow{2}{*}{$O A$} & \multirow{2}{*}{$K C$} \\
\cline { 2 - 5 } & $\boldsymbol{P A}$ & $\boldsymbol{U A}$ & $\boldsymbol{P A}$ & $\boldsymbol{U A}$ & & \\
\hline NDBSUI & 91 & 98.39 & 98.8 & 93.62 & 95.51 & 0.9076 \\
\hline $\boldsymbol{E B B \boldsymbol { I }}$ & 100 & 88.51 & 87 & 100 & 93.51 & 0.8701 \\
\hline NDBI & 97.5 & 89.6 & 87.8 & 97.01 & 92.86 & 0.8564 \\
\hline $\boldsymbol{U I}$ & 93.5 & 92.4 & 92 & 93.24 & 92.81 & 0.8561 \\
\hline
\end{tabular}

Table 2. Compared accuracies

At larger scales of AOIs, the visual patterns show that the three others indices had helped to highlight built-up from other land cover categories, especially in the built-up and wet soil dominating AOI (Fig.11). Moreover, in the third
AOI mixing built-up, dry soils, rocks and stones, the discrimination is more effective and there is low confusion than in the three other indices. Table 3 gives the details of the accuracies in the AOIs.

\begin{tabular}{|l|c|c|c|c|c|c|c|c|}
\hline \multirow{2}{*}{ Index } & \multicolumn{2}{|c|}{ AOI 1 } & \multicolumn{2}{c|}{ AOI 2 } & \multicolumn{2}{c|}{ AOI 3 } & \multicolumn{2}{|c|}{ Average AOIs } \\
\cline { 2 - 9 } & $O A$ & $K C$ & $O A$ & $K C$ & $O A$ & $K C$ & $O A$ & $K C$ \\
\hline NDBSUI & 100 & 1 & 96.5 & 0.92 & 96.8 & 0.93 & 97.8 & 0.95 \\
\hline$E B B I$ & 98.9 & 0.97 & 96.5 & 0.93 & 91.7 & 0.84 & 95.7 & 0.91 \\
\hline NDBI & 96.8 & 0.93 & 94.1 & 0.88 & 95.7 & 0.91 & 95.6 & 0.91 \\
\hline$U I$ & 97.8 & 0.95 & 94.2 & 0.88 & 93.6 & 0.87 & 95.2 & 0.90 \\
\hline
\end{tabular}

Table 3. Compared accuracies in the AOIs

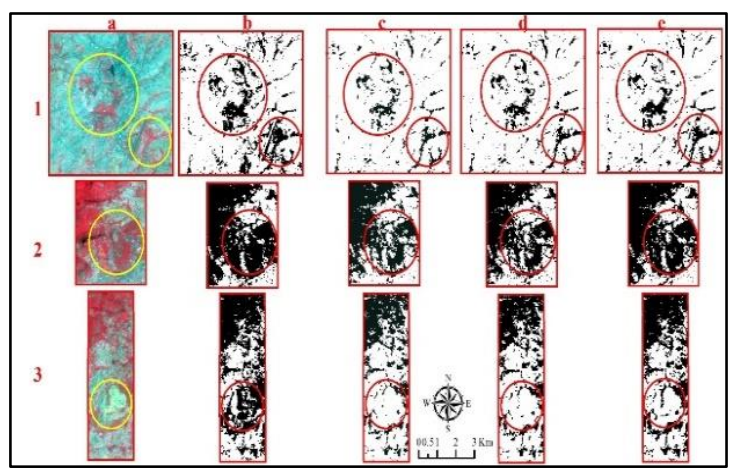

Figure 11. The binary indices maps on the AOIs. From top to bottom, 1, 2 and 3 represent the AOIs. From the left to the right, $\boldsymbol{a}, \boldsymbol{b}, \boldsymbol{c}, \boldsymbol{d}$ and $\boldsymbol{e}$ refer to Landsat-8 OLI original image, NDBSUI, EBBI, NDBI and UI. The circles represent the areas with different detection patterns.

The last assessment of the NDBSUI efficiency was comparing the statistics of land cover category areas. Using the binary classified image, the built-up areas extracted were compared (Tabl.4). According to the classified image, the built-up is extended over 13531.32 hectares and the other land cover categories cover 18218.97 hectares, for a total of 31750.29 hectares. The NDBSUI on its side detects built-up on 15943.95 hectares, and the non-built-up over 15806.25 hectares, for a total of 31750.2 hectares. This area is higher by 2412.63 hectares from classified image built-up area (Fig.12). When extending statistical analysis to other indices, the built-up areas of EBBI, NDBI and UI are higher by, respectively, 5035.41 hectares, 4583.34 hectares and 3328.29 hectares from the classified reference image. This confirms the efficiency of the NDBSUI to reduce the confusion between classes, better than the three other indices.

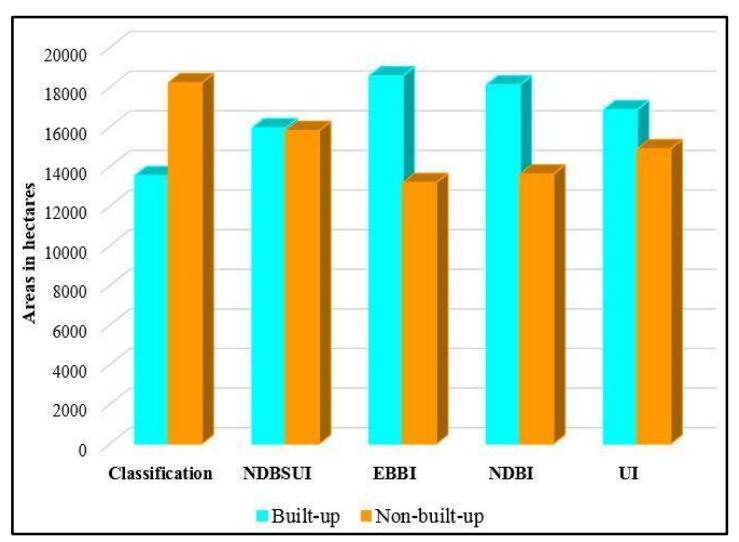

Figure 12. Built-up area per index 


\subsection{Test-validation on the five independents sites}

The first two cities of Yokadouma and Kumba, represent the deep rainy season respectively with bimodal and monomodal rainfall (see Fig.2a), where soil is less exposed, gave the best visual as well as statistical appraisal of the built-up area. The visual patterns (fig.13) as well as the high overall accuracies and kappa coefficients testify the satisfactory application of NDBSUI (Yokadouma: $\mathrm{OA}=98.9 \% \& \mathrm{KC}=0.88$; Kumba: $\mathrm{OA}=97.5 \%$ \& $\mathrm{KC}=0.947$ ), comparatively to EBBI, NDBI and UI.

Furthermore, the test was performed for the cities of Foumban and Ngaoundéré, representing the bio-climatic transition between the wet and the dry lands. They are respectively the validation sites for the western highlands and the high Guinea savannah, with a low forest cover and mixing of soil with the built-up. Visually, the NDBSUI has provided a better appraisal of the built-up than the other indices have (Fig.13). Statistically, the overall accuracies and kappa coefficients scores support the high performance of the NDBSUI (Foumban: $\mathrm{OA}=97.06 \%$ \& $\mathrm{KC}=0.918$; Ngaoundéré: $\mathrm{OA}=95.3 \%$ \&C $=0.89$ ).

The last validation site is the city of Garoua, corresponding the sub-saharian bio-climatic zone, mostly dominated by sands and transitioning from the shrubs to the desert. The NDBSUI after highlighting the built-up area according to the stacked image and the classified map had shown less confusion with the non-built-up area as well as the highest accuracy scores $(\mathrm{OA}=74.8 \%$ \& $\mathrm{KC}=0.42$ ).

The overall accuracies and kappa coefficients are recorded in Table 4.

\begin{tabular}{|c|c|c|c|c|c|c|c|c|c|c|}
\hline Inde & \multicolumn{2}{|c|}{ Yokadouma } & \multicolumn{2}{c|}{ Kumba } & \multicolumn{2}{c|}{ Foumban } & \multicolumn{2}{c|}{ Ngaoundéré } & \multicolumn{2}{c|}{ Garoua } \\
\cline { 2 - 12 } x & $\boldsymbol{O A}$ & $\boldsymbol{K C}$ & $\boldsymbol{O A}$ & $\boldsymbol{K C}$ & $\boldsymbol{O A}$ & $\boldsymbol{K C}$ & $\boldsymbol{O A}$ & $\boldsymbol{K C}$ & $\boldsymbol{O A}$ & $\boldsymbol{K C}$ \\
\hline $\boldsymbol{N D B}$ & 98. & 0.8 & 97 & 0.9 & 97.0 & 0.9 & 95.2 & 0.8 & 7.8 & 0.4 \\
$\boldsymbol{S U I}$ & $9 \%$ & 8 & $5 \%$ & 47 & $6 \%$ & 18 & $9 \%$ & 94 & $6 \%$ & 21 \\
\hline $\boldsymbol{E B \boldsymbol { B }}$ & 97 & 0.8 & 92. & 0.8 & 76.2 & 0.4 & 91.2 & 0.8 & 63.6 & 0.2 \\
$\boldsymbol{I}$ & $9 \%$ & 22 & $2 \%$ & 08 & $5 \%$ & 57 & $\%$ & 14 & $8 \%$ & 2 \\
\hline $\boldsymbol{N D B}$ & 98 & 0.8 & 97 & 0.9 & 65.4 & 0.3 & 88.3 & 0.7 & 56.5 & 0.1 \\
$\boldsymbol{I}$ & $\%$ & 24 & $8 \%$ & 52 & $\%$ & 0 & $\%$ & 57 & $\%$ & 05 \\
\hline $\boldsymbol{U} \boldsymbol{I}$ & 99 & 0.9 & 97 & 0.9 & 75.6 & 0.4 & 91.2 & 0.7 & 58.4 & 0.0 \\
& $\%$ & 18 & $1 \%$ & 38 & $8 \%$ & 94 & $\%$ & 97 & $\%$ & 24 \\
\hline
\end{tabular}

Table 4. Validation sites accuracy

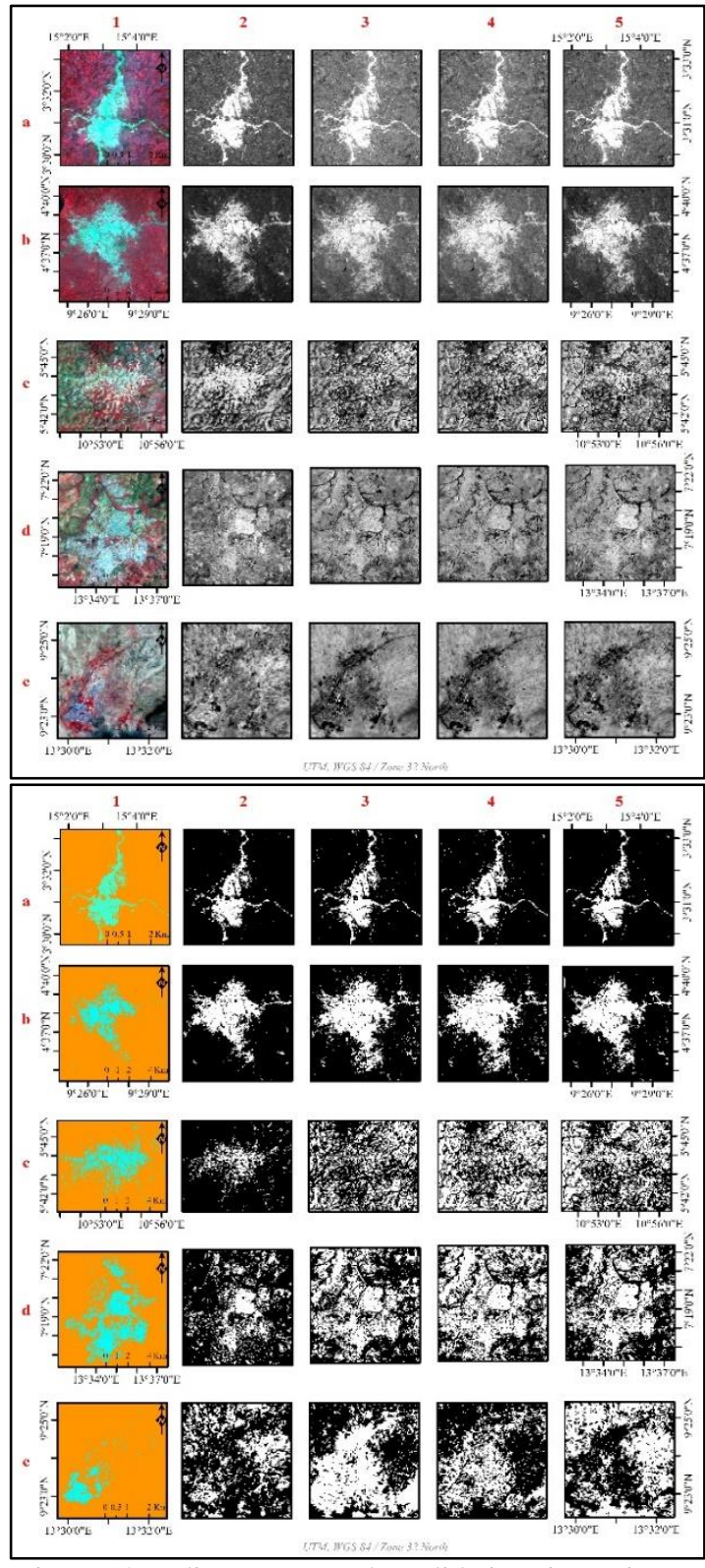

Figure 13. Indices maps on the validation sites. The top box maps represent the Landsat8-OLI and the indices maps in stretched values. Read top-down. Yokadouma

(a), Kumba (b), Foumban (c), Ngaoundéré (d) and Garoua (e). Read left-to-right. Landsat-OLI (1), NDBSUI (2), EBBI (3), NDBI (4) and UI (5). The bottom maps box represents the classification and the indices maps in binary values. Read in the same order.

\section{CONCLUSIONS}

This study has addressed the problem of mixed-pixels between built-up and other surrounding features. The theory related to the red, SWIR1 and SWIR2 wavelengths in the built-up extraction, as well as reflectance analysis on the AOIs has helped to understand the mixed pixels and create the NDBSUI algorithm. The resulting accuracies were satisfactory on the experimental site of Yaoundé, as well as in the five validation sites. Despite its efficiency in extracting and unmixing built-up from surrounding features, some uncertainties related to the spatial resolution constraints that were part of challenges to 
overcome, and the bioclimatic and ecological issues that emphasize mixed pixels extension remain to be addressed. Ongoing improvements are actually conducted to point out these noise issues from the brightness temperature and darkness approach.

\section{AKNOWLEDGEMENTS}

Authors are grateful to USGS for the satellite images freely available. They especially appreciate the support of StatsN'Maps consulting firm management, for initiating and directing this work since its presentation the ISPRS 2020 annual conference.

\section{REFERENCES}

As-syakur, A.R.; Adnyana, I.W.S.; Arthana, I.W.; Nuarsa, I.W., 2012. Enhanced Built-Up and Bareness Index (EBBI) for Mapping Built-Up and Bare Land in an Urban Area. Remote Sens., 4, 2957-2970.

Bangira, T.; Alfieri, S.M.; Menenti, M.; Van Niekerk, A.; Vekerdy, Z., 2017. A Spectral Unmixing Method with Ensemble Estimation of Endmembers: Application to Flood Mapping in the Caprivi Floodplain. Remote Sens. 9, 1013.

Chen, J.; Li, M.; Yongxue, L.; Shen, C.; Hu, W., 2010. Extract residential areas automatically by New Built-up Index. Proceedings of the 2010 18th International Conference on Geoinformatics, Beijing, China, 18-20 June, IEEE.

Congalton, R.G. and Green, K. 2009. Assessing the Accuracy of Remotely Sensed Data-Principles and Practices. 2nd ed. CRC Press: Boca Raton, p.183.

Ettehadi Osgouei, P., Kaya, S., Sertel, E., Alganci, U., 2019. Separating Built-Up Areas from Bare Land in Mediterranean Cities Using Sentinel-2A Imagery. Remote Sens., 11, 345 .

Gonzalez, R., 2002. Digital Image Processing 3nd Edition. Prentice Hall. pp. 232-233.

Herold, M., Gardner, M. E. and Roberts, D. A. 2003. Spectral resolution requirements for mapping urban areas. IEEE Transactions on Geoscience and Remote Sensing, (41), 9, 1907-1919.

Hanqiu, X., 2010. Analysis of Impervious Surface and its Impact on Urban Heat Environment using the Normalized Difference Impervious Surface Index (NDISI). Photogramm. Eng. Remote Sens., 76.

Kawamura, M., Jayamana. S., Tsujiko, Y., 1996. Relation between social and environmental conditions in Colombo Sri Lanka and urban index estimated y satellite remote sensing data. Int. Arch. Photogram. Remote Sens., 31, 321-326

Kokaly, R.F., Clark, R.N., Swayze, G.A., Livo, K.E., Hoefen, T.M., Pearson, N.C., Wise, R.A., Benzel, W.M., Lowers, H.A., Driscoll, R.L., and Klein, A.J., 2017. USGS Spectral Library Version 7: U.S. Geological Survey Data Series 1035, p. 61.
Ngandam Mfondoum, A.H. et al. Extraction of Built-up features in complex biophysical environments by using a landsat bands ratio: results of the first tests. Proceedings of the ASPRS 2020 annual conference virtual session, Washington, USA, 22-26 June, p.15.

Schueler, T.R., 1994. The importance of imperviousness. Routledge: New York, USA, p.100-111.

USGS, 1990. The spatial data transfer standard. Draft

Rasul, A., Balzter, H., Gaylan, R., Ibrahim, F., Hameed, H.M., Wheeler, J., Adamu, B., Ibrahim, S., Najmaddin, P.M., 2018. Applying Built-Up and Bare-Soil Indices from Landsat 8 to Cities in Dry Climates. Land., 7, 81.

Xu, H., 2008. A new index for delineating built-up land features in satellite imagery. Int. J. Remote Sens., 29, 4269 -4276 .

Zha, Y., Gao, J., Ni, S.,2003. Use of normalized difference built-up index in automatically mapping urban areas from TM imagery. Int. J. Remote Sens., 24, 583-594. 